\title{
sciendo
}

\section{Consumers' perception on the use of cognitive computing}

\author{
Corina PELAU \\ Bucharest University of Economic Studies, Bucharest, Romania \\ corina.pelau@fabiz.ase.ro \\ Maria BARBUL \\ Bucharest University of Economic Studies, Bucharest, Romania \\ mariabarbul@gmail.com
}

\begin{abstract}
In a world dominated by data, information is one of the most important resources. But simply collecting and storing data is not enough, as data has to be transformed into information. Researchers agree on the fact that both computing power and analytical methods allow this at an unprecedented level. Given the consistent and wide applicability of such systems and technologies today, the present work goes into possible uses of cognitive computing and sets its focus on the retail sector. Cognitive computing generally helps with consumer profiling, deriving their preferences, delivering suitable product recommendations, and contouring the consumer experience when interacting with companies. The main aim of the present work is to investigate consumer experiences with the help of cognitive computing and lay ground for further research on this topic. In the following sections of the present article, we define the concept of cognitive computing, with regard to its meaning for multiple, diverse data streams and types. We then empirically investigate the use of CC for shaping and enriching consumer experiences with the help of cognitive virtual assistants (CVAs). After conducting quantitative research, we discuss differences in perceptions between two age groups (under and over 40 years).
\end{abstract}

Keywords: cognitive computing, artificial intelligence, big data, consumer experiences.

\section{Introduction}

The emergence of big data, artificial intelligence, cognitive computing and further human-like enabling software and technologies for machines and computers shape our present. Previous research agrees on a paradigm shift and on the fact that we have already entered a cognitive era (Gupta, et al. 2018) and even experienced a so-called fourth industrial revolution (Huang \& Rust 2018). Cognitive computing, manifested through new technologies, machines and systems with the help and advancement of programmed algorithms that exhibit aspects of human cognition is increasingly utilized in data analysis, services, interactions and represents a major source of innovation for today's society (Rust \& Huang, 2014). This recent cognitive era relies on "the power of supercomputers" (Duan et al., 2019) and contributes to the establishment of an impressive ongoing partnership between humans and machines, whereby the beneficial interaction of human and artificial intelligence (AI) is brought to the fore (Pelau et al., 2021). Cognitive systems use artificial intelligence to break down and understand different human-like data, to find connections between countless types of unstructured data, to carry out in-depth analyzes, to formulate predictions and to convey insights to people in a comprehensible way. This not only leads to the prosperity of the actors involved, but also defines a new way in which data and information are perceived and used, while emphasizing the importance of using additional data processing measures. If implemented successfully, cognitive computing (CC) offers a vast range of benefits for individuals and society. For the health-care system, for instance, cognitive computing enables machines to set faster diagnoses and to offer personalized 
treatment. In finance, cognitive systems are able to make accurate investment predictions and provide fact-based financial advice (Topol, 2019). In customer care and in retail, the technology of cognitive computing can accurately describe consumer profiles, easily personalize customer relationships, and predict future trends (Demirkan et al., 2015; Busu et al., 2018). In entertainment and sports, cognitive computing is able to assist and provide coaches with valuable information with the help of sensor-tracking cameras that spot and analyze certain hidden performance insights.

PICBE |

640

\section{Literature review on the emergence of cognitive computing}

In recent years, the rapid accumulation of consumer and transactional data has resulted in the formation of very large and complex databases. This significant amount of consumer data offers unique opportunities, but it is needless to say that there is no manual solution to gaining valuable information. However, programmed solutions offered by computer-aided, algorithmic methods, known under the concept of cognitive computing, are available for data optimization and are able to carry out tasks with minimal human intervention (Cui et al., 2006).

\section{Meaning and importance of data}

It is for sure safe to say that we live in a data-driven world. The proverb Knowledge is power still finds new meanings, as the power of today's data transformed with the help of the right methods into valuable information offers unlimited possibilities and precious knowledge. The constantly generated and collected volume of data is of unimaginable proportions, yet still, with the right intelligent technologies to record, store and use these enormous data sets, one may find himself in charge of valuable information. The actual challenge, however, lies in finding the appropriate process for this enormous, constantly growing but valuable amount of data, to further obtain useful knowledge from it and to use it according to various needs.

The still ongoing and unstoppable trend towards online data generation constantly increases the rate of data volume growth and the possibilities of data collection and processing. Summarized under the concept of big data, this digitization of information and its availability (Berger et al. 2020) shape many activities, domains, and fields. From simple georeferenced data to the subsequent development of storage capacities and furthermore to the use of powerful computer processing functions, the comprehensive concept of big data relates to the aforementioned growing amount of data, to the collection and storage of this data, and to the processing and use of the results. Big data can be easily and precisely characterized by the socalled 5Vs: Volume, Variety, Veracity, Velocity and Value (Fosso-Wamba et al., 2015; Grover \& Kar, 2017; Gupta et al., 2018), which, according to Chen et al. (2016), are also to be seen as five inherent challenges that need to be overcome. These simply formulated data properties indicate the need to generate information from the collected data and the fact that conventional database management (DBMS) is no longer adequate for high volumes of data. Therefore, new technologies such as advanced data analytics gain popularity and offer the required efficiency to use data processing and transformation (Appel et al. 2017; Pop et al., 2017; Zbuchea et al., 2019).

\section{Cognitive Computing}

Cognitive science has emerged as an interdisciplinary subject that studies the circulation of information in the human brain. Cognitive technologies are an evolution in computing that mimics some aspects of human thought processes on a larger scale (estimating correlations, testing hypotheses, making predictions and inferences, drawing conclusions). The multi-faceted 
concept of cognitive computing, as an extensive, application-wide technology platform, is based on complex scientific disciplines such as artificial and augmented intelligence, information knowledge management systems, cloud computing and moreover includes numerous operating technologies such as: machine learning (ML), deep learning methods, artificial neural networks $(\mathrm{ANN})$, natural language processing (NLP), information retrieval (IR), reasoning, Bayesian statistics, and human computer interaction (HCI) (Sabharwal et al., 2020).

Previous research connects frequently the concept of cognitive computing to that of (big) data (Reynolds, 2015). As a synergy between data science and cognitive science, cognitive computing was developed as an interdisciplinary approach and has become the field of study that incorporates both research areas into advanced computer technologies (Hurwitz, 2015; Varadarajan et al., 2020). In search for a solution to manage the previously described volume of data and to keep up with the still ongoing data generation, the concept of cognitive computing came to life. Not only do cognitive systems solve these two problems, but in addition they try to unlock and find meaning of data in all its varieties and contexts, eliminating unwanted data noise. Furthermore, human incapacities, such as biases and time limitations are obstructed, allowing faster, more accurate data processing.

Advanced cognitive computer systems are intended to help with strategic, economic and political decisions and thus accelerate anticipated global trends for consumers and society. Cognitive computing thus contributes to the redesign of an entire economic sector: today's experience economy (Dziewanowska, 2015). Consumer experiences can now be optimized and be simply managed by software. There is currently a significant paradigm shift in terms of interaction, perception, emotional education, and the design of consumer experiences (McCollKennedy et al., 2019; Pelau et al., 2019). The difference between traditional demographic and cognitive (based on the application of cognitive computing) marketing can be seen without a doubt. Marketing measures and customer experiences are no longer just based on the place, time and age of the consumer, but are redefined and fundamentally redesigned with the help of dynamically generated knowledge. Numerous cognitive systems, intelligent services and expanded APIs enable marketers to approach consumers, build dynamic relationships and develop new preferences, or even new needs and future trends. The current interactions between customers and organizations in the digital, physical, and social arenas generate data about customer experiences, which can be both structured and unstructured (Zaki, 2019). While structured consumer experience data can be presented in the form of numbers (e.g. sales data, localization coordinates or results of surveys on customer satisfaction), unstructured data usually consists of multimedia formats such as text, sound, images and videos posted online. In addition, consumer data to be analyzed can be either requested or unsolicited (Holmlund et al., 2020).

\section{Methodology}

Given the increased trend of companies using cognitive computing for various customer related activities, the objective of our research consists in determining the attitude of consumers towards cognitive systems. Our study tries to empirically assess the effects of cognitive computing on the consumer's behavior and experiences as well as to investigate how cognitive systems are perceived by consumers. In order to test these objectives, we have developed a questionnaire, including 50 questions about the attitude of consumers regarding different situations related to the topic. The following aspects were tested in relation to cognitive systems and cognitive virtual assistants: general knowledge, general consumer attitudes, efficiency, enthusiasm, fear and appreciation of personal data. The last section was dedicated to collecting the demographic 
information. Because the concept of cognitive computing is often not used colloquially, the respondents were provided with an explanation of both the concept of cognitive computing and the concepts and applications of cognitive virtual assistants. By this means, certain differences in understanding have tried to be covered. The items for measuring consumers' perception, have been measured with Likert Scale questions, having values between 1 (total disagreement) and 7 (total agreement). The sample of the survey consisted of 141 consumers with different backgrounds regarding age, gender, education and income. The research was conducted in

PICBE | 642 Romania, based on an online self administered questionnaire, created with Google Forms. The sample pool was recruited randomly. The reliability and internal consistency of the used scale has been measured with Cronbach's Alpha coefficient in SPSS, showing a good validity $(\alpha=0.894)$.

The results of the survey have been concluded based on a discriminant analysis in IBM SPSS Statistics 25, with the purpose of determining significant differences between different sample groups. The significant differences between respondents' choices have been tested depending on the demographic characteristic of the consumer age (people younger than 40 years and people older than 40 years. The sample included 89 people younger than 40 years and 52 people older than 40 .

\section{Results and discussions}

The results of our research mainly focus on the difference between the two age groups of people: older than 40 years and people younger than 40 years. The results show that in the case of cognitive computing, which is still a rather unfamiliar system for consumers, there are only average significant differences, as can be observed in the tables 2-6. Results marked with bold letters show significant differences that are also discussed in the present article.

General consumer knowledge and attitudes regarding cognitive computing For the first two sections of the survey, when comparing the answers by the two age groups (under and over 40 years old) - the discriminant analysis shows a significant difference in terms of cognitive applications in relation to consumer interaction (item 5). Although the majority of respondents are not familiar with the applications of cognitive systems, the level of knowledge of the two groups is significantly different $(\mathrm{F} 5=3.171, \mathrm{p} 5=0.077)$. As expected, the younger age group, compared to the older one, benefit from more knowledge on this topic.

Table 1. Discriminant analysis regarding knowledge and attitudes of consumers on cognitive computing and cognitive systems

\begin{tabular}{|l|l|l|l|l|}
\hline \multicolumn{1}{|c|}{ Item } & \multicolumn{1}{|c|}{$\begin{array}{c}\overline{\mathbf{x}} \\
\text { Age: }<\mathbf{4 0}\end{array}$} & $\begin{array}{c}\overline{\mathbf{x}} \\
\text { Age: }>\mathbf{4 0}\end{array}$ & \multicolumn{1}{|c|}{ F } & $\begin{array}{c}\mathbf{p} \\
\text { Value }\end{array}$ \\
\hline $\begin{array}{l}\text { 1. Before reading the definition, I knew what cognitive computing } \\
\text { systems are and what the concept of "Cognitive Computing" refers } \\
\text { to. }\end{array}$ & 4.02 & 3.60 & 1.332 & 0.250 \\
\hline $\begin{array}{l}\text { 2. I am familiar with the areas in which cognitive computing systems } \\
\text { can be applied. }\end{array}$ & 3.94 & 3.77 & 0.252 & 0.616 \\
\hline $\begin{array}{l}\text { 5. I am aware of the types of applications that cognitive } \\
\text { computing systems can have in interacting with consumers. }\end{array}$ & $\mathbf{3 . 7 6}$ & $\mathbf{3 . 1 3}$ & $\mathbf{3 . 1 7 1}$ & $\mathbf{0 . 0 7 7}$ \\
\hline
\end{tabular}




\begin{tabular}{|l|l|l|l|l|}
\hline \multicolumn{1}{|c|}{ Item } & \multicolumn{1}{|c|}{$\begin{array}{c}\overline{\mathbf{x}} \\
\text { Age: }<\mathbf{4 0}\end{array}$} & $\begin{array}{c}\overline{\mathbf{x}} \\
\text { Age: }>\mathbf{4 0}\end{array}$ & F & $\begin{array}{c}\text { p } \\
\text { Value }\end{array}$ \\
\hline $\begin{array}{l}\text { 6. I believe that in the current context, characterized by the evolution } \\
\text { of Big Data and the Internet of Things, cognitive computing systems } \\
\text { are necessary for the correct use of data. }\end{array}$ & 5.25 & 5.21 & 0.016 & 0.899 \\
\hline $\begin{array}{l}\text { 7. I believe that cognitive computing systems can filter data better } \\
\text { than humans. }\end{array}$ & 5.12 & 5.17 & 0.037 & 0.848 \\
\hline $\begin{array}{l}\text { 8. I believe that cognitive computing systems can perceive } \\
\text { information better than humans. }\end{array}$ & 4.60 & 4.77 & 0.362 & 0.549 \\
\hline $\begin{array}{l}\text { 9. I believe that cognitive computing systems can make better } \\
\text { decisions than humans. }\end{array}$ & 4.10 & 4.21 & 0.137 & 0.711 \\
\hline $\begin{array}{l}\text { 10. I believe that cognitive computing systems are smarter than } \\
\text { humans. }\end{array}$ & 4.06 & 3.75 & 0.929 & 0.337 \\
\hline $\begin{array}{l}\text { 11. I consider that the involvement of cognitive computing systems } \\
\text { in the marketing systems of different companies is beneficial for } \\
\text { those companies. }\end{array}$ & 5.58 & 5.52 & 0.093 & 0.761 \\
\hline $\begin{array}{l}\text { 12. I believe that the involvement of cognitive computing systems in } \\
\text { the marketing systems of different companies is beneficial for the } \\
\text { consumer experience. }\end{array}$ & 5.01 & 4.87 & 0.314 & 0.576 \\
\hline $\begin{array}{l}\text { 13. I believe that the introduction of cognitive computing systems for } \\
\text { solving routine tasks in the daily activities of a company contributes } \\
\text { to increasing efficiency. }\end{array}$ & 5.73 & 5.58 & 0.455 & 0.501 \\
\hline
\end{tabular}

PICBE |

Source: Authors' own research.

\section{Efficiency of cognitive systems in shaping consumer experiences}

When evaluating consumers' perception on efficiency of cognitive systems by age group, different opinions emerged for two items in this part of the questionnaire. First, as far as the personalized relationship with a company is concerned $(\mathrm{F} 20=4.616, \mathrm{p} 20=0.033)$, younger people $(\overline{\mathrm{x}}<40=3.64)$ are less disturbed by a personalized and AI-driven relationship with a company than older people $(\overline{\mathrm{x}}>40=4.34)$. Second, it is interesting to see that the ability of robot reporters is also differently perceived. Those over 40 years of age $(\bar{x}>40=4.25)$ offer more trust to cognitive systems for reporting sport events $(\mathrm{F} 24=2.831, \mathrm{p} 24=0.095)$, compared to younger people $(\overline{\mathrm{x}}<40=3.75)$.

Table 2. Discriminant analysis regarding efficiency of cognitive systems in shaping consumer experiences

\begin{tabular}{|l|l|l|l|l|}
\hline \multicolumn{1}{|c|}{ Item } & \multicolumn{1}{|c|}{$\begin{array}{c}\overline{\mathbf{x}} \\
\text { Age: }<\mathbf{4 0}\end{array}$} & \multicolumn{1}{|c|}{$\begin{array}{c}\overline{\mathbf{x}} \\
\text { Age: }>\mathbf{4 0}\end{array}$} & \multicolumn{1}{|c|}{$\mathbf{F}$} & $\begin{array}{c}\mathbf{p} \\
\text { Value }\end{array}$ \\
\hline $\begin{array}{l}\text { 15. I believe that a CVA (Cognitive Virtual Assistant) can better } \\
\text { understand the needs of consumers. }\end{array}$ & 4.34 & 4.38 & 0.031 & 0.861 \\
\hline 16. I believe that a cognitive computing system can anticipate the & 4.80 & 4.92 & 0.278 & 0.599 \\
\hline
\end{tabular}




\begin{tabular}{|c|c|c|c|c|}
\hline Item & $\begin{array}{c}\bar{x} \\
\text { Age: }<40\end{array}$ & $\begin{array}{c}\bar{x} \\
\text { Age: }>40\end{array}$ & $\mathbf{F}$ & $\begin{array}{c}\mathbf{p} \\
\text { Value }\end{array}$ \\
\hline \multicolumn{5}{|l|}{ needs of consumers. } \\
\hline $\begin{array}{l}\text { 17. I believe that a CVA can make the right choices for a } \\
\text { consumer, based on his preferences. }\end{array}$ & 4.74 & 4.65 & 0.113 & 0.737 \\
\hline $\begin{array}{l}\text { 18. I believe that a CVA can be more effective in maintaining } \\
\text { customer relations than employees of the department for customer } \\
\text { relations. }\end{array}$ & 3.98 & 4.19 & 0.503 & 0.479 \\
\hline $\begin{array}{l}\text { 19. I believe that companies must exploit the benefits of cognitive } \\
\text { systems to maintain relationships with customers. }\end{array}$ & 4.74 & 5.02 & 1.149 & 0.286 \\
\hline $\begin{array}{l}\text { 20. It bothers me to know that my relationship with a company } \\
\text { is based on artificial intelligence, even though it is personalized. }\end{array}$ & 3.64 & 4.35 & 4.616 & $\mathbf{0 . 0 3 3}$ \\
\hline $\begin{array}{l}\text { 21. I believe that direct interaction with a CVA to solve various } \\
\text { problems that require telephone assistance from a company is } \\
\text { effective. }\end{array}$ & 4.16 & 4.27 & 0.138 & 0.711 \\
\hline $\begin{array}{l}\text { 22. I prefer to be helped by a cognitive computing system when I } \\
\text { have to solve various banking problems. }\end{array}$ & 3.80 & 4.15 & 1.342 & 0.249 \\
\hline $\begin{array}{l}\text { 23. I prefer to be helped by a cognitive computing system when } \\
\text { purchasing an item of clothing. }\end{array}$ & 3.38 & 3.67 & 0.811 & 0.369 \\
\hline $\begin{array}{l}\text { 24. In the case of sporting events, I believe that cognitive } \\
\text { computing systems can render information and moods } \\
\text { captured in matches better than specialized reporters. }\end{array}$ & 3.75 & 4.25 & 2.831 & 0.095 \\
\hline $\begin{array}{l}\text { 25. I believe that cognitive computing systems can write truthful } \\
\text { news. }\end{array}$ & 4.00 & 4.27 & 0.762 & 0.384 \\
\hline $\begin{array}{l}\text { 26. I believe that people are behind the most effective marketing } \\
\text { campaigns, not artificial intelligence. }\end{array}$ & 5.45 & 5.29 & 0.443 & 0.507 \\
\hline $\begin{array}{l}\text { 27. I believe that behind the most effective marketing campaigns is } \\
\text { artificial intelligence, not people. }\end{array}$ & 3.10 & 3.35 & 0.668 & 0.415 \\
\hline
\end{tabular}

Source: Authors' own research.

Enthusiasm of consumers for cognitive computing and cognitive systems Tested according to the age structure and divided into the two corresponding groups (under and over 40 years old), the discriminant analysis also revealed differences in the evaluation of two items in the fourth section of the questionnaire. First, the older group ( $>40$ years old) shows interest towards including cognitive systems in customer relationships, while the younger group ( $<40$ years) tends to disagree, aspect proven by the lower mean value $(\mathrm{F} 34=4.089, \mathrm{p} 34=0.045)$. This is also proven by the difference in evaluation of item $35(\mathrm{~F} 35=11.848$, p35 $=0.001)$. The older group shows a level of agreement above average, when considering the importance of cognitive systems for shaping customer relationships $(\overline{\mathrm{x}}>40=5.40)$, while the younger group of respondents $(\overline{\mathrm{x}}<40$ $=4.51$ ) rates this statement below the average. 
Table 3. Discriminant analysis regarding consumers' enthusiasm for cognitive systems

\begin{tabular}{|c|c|c|c|c|}
\hline Item & $\begin{array}{c}\bar{x} \\
\text { Age: }\end{array}<40$ & $\begin{array}{c}\bar{x} \\
\text { Age: }>40\end{array}$ & $\mathbf{F}$ & $\begin{array}{c}p \\
\text { Value }\end{array}$ \\
\hline $\begin{array}{l}\text { 28. I am pleasantly impressed by the technology of cognitive } \\
\text { computing systems. }\end{array}$ & 5.13 & 4.98 & 0.339 & 0.561 \\
\hline $\begin{array}{l}\text { 29. I am fascinated by the possibility of human-computer } \\
\text { interaction. }\end{array}$ & 5.17 & 5.12 & 0.036 & 0.849 \\
\hline $\begin{array}{l}\text { 30. I want to be able to understand the technology behind cognitive } \\
\text { computing systems. }\end{array}$ & 5.20 & 5.44 & 0.665 & 0.416 \\
\hline $\begin{array}{l}\text { 31. I believe that cognitive computing systems are beyond me, } \\
\text { because I do not understand what is exactly behind them. }\end{array}$ & 3.66 & 4.06 & 1.585 & 0.210 \\
\hline $\begin{array}{l}\text { 32. The fact that I do not understand what is hidden behind } \\
\text { cognitive computing systems worries me. }\end{array}$ & 2.84 & 2.69 & 0.250 & 0.618 \\
\hline $\begin{array}{l}\text { 33. The evolution and applicability of cognitive computing systems } \\
\text { seem to me to be areas that need to be further exploited. }\end{array}$ & 5.89 & 6.06 & 0.667 & 0.415 \\
\hline $\begin{array}{l}\text { 34. I believe that cognitive computing systems must not be } \\
\text { absent from companies' interaction with consumers. }\end{array}$ & 4.76 & 5.33 & 4.089 & 0.045 \\
\hline $\begin{array}{l}\text { 35. I believe that cognitive computing systems are important } \\
\text { for shaping companies' relationships with customers. }\end{array}$ & 4.51 & 5.40 & 11.84 & 0.001 \\
\hline
\end{tabular}

Source: Authors' own research.

\section{Fear of intrusion of cognitive systems into the private sphere}

Considering the fact that cognitive systems possess abilities still unknown by the public, which allow them to collect various types of data, fear of intrusion should also be assessed. Taking a closer look at the comparison of the two age groups, three main differences are to be observed in this area. First, people over 40 years rate themselves as being more uncertain about the interaction with a CVA. Also, in this regard, the same age group ( $>40)$ admits the fact that CVAs are able to invade their private sphere. On the other side, people under 40 years, seem to be less disturbed, or aware of these matters. Second, based on the results of the discriminant analysis (see table 5), the older age group rates higher on item $42(\mathrm{~F} 42=5.628$, p42 $=0.019)$, thus having a significantly better consideration of the help offered by cognitive systems in helping companies process large volumes of data.

Table 4. Discriminant analysis regarding consumers' fear of intrusion of cognitive systems into their private spheres

\begin{tabular}{|c|c|c|c|c|}
\hline Item & $\begin{array}{c}\bar{x} \\
\text { Age: }<40\end{array}$ & $\begin{array}{c}\bar{x} \\
\text { Age: }>40\end{array}$ & $\mathbf{F}$ & $\begin{array}{c}\mathbf{p} \\
\text { Value }\end{array}$ \\
\hline $\begin{array}{l}\text { 36. I consider that cognitive computing systems can maintain my private } \\
\text { sphere. }\end{array}$ & 4.37 & 4.37 & 0.000 & 0.987 \\
\hline 37. It bothers me that cognitive computing systems use my data. & 4.17 & 4.67 & 2.525 & 0.114 \\
\hline
\end{tabular}




\begin{tabular}{|c|c|c|c|c|}
\hline Item & $\begin{array}{c}\bar{x} \\
\text { Age: }<40\end{array}$ & $\begin{array}{c}\bar{x} \\
\text { Age: }\end{array}>40$ & $\mathbf{F}$ & $\begin{array}{c}\mathbf{p} \\
\text { Value }\end{array}$ \\
\hline $\begin{array}{l}\text { 38. I consider that the transmission of personal data to a CVA in the } \\
\text { dialogue with a company is uncertain. }\end{array}$ & 3.66 & 4.35 & 4.957 & 0.028 \\
\hline 39. I believe that interacting with a CVA can invade my private sphere. & 3.79 & 4.48 & 4.312 & 0.040 \\
\hline $\begin{array}{l}\text { 40. I consider that the suggestions received from a CVA influence my } \\
\text { purchasing decisions in a direct way that I do not want. }\end{array}$ & 3.49 & 3.81 & 1.124 & 0.291 \\
\hline $\begin{array}{l}\text { 41. I consider that the purpose of cognitive computing systems applied in } \\
\text { interaction with consumers is to control consumers. }\end{array}$ & 3.58 & 4.04 & 1.764 & 0.186 \\
\hline $\begin{array}{l}\text { 42. I believe that the purpose of cognitive computing systems applied in } \\
\text { interaction with consumers is to help firms move towards coherent } \\
\text { processing of large volumes of data. }\end{array}$ & 5.51 & 6.06 & 5.628 & 0.019 \\
\hline
\end{tabular}

PICBE |

\section{Consumer appreciation of personal data}

In the further analysis according to the age groups, four interesting and meaningful differences emerge when considering the appreciation of personal data. Differences arise with regard to data transfer in communication with a company $(\mathrm{F} 47=15,719, \mathrm{p} 47=0,000)$. Older people (over 40 years of age) tend to pay more attention to their personal information $(\overline{\mathrm{x}}>40=6.48)$, while people under 40 years of age tend to pay less attention to it $(\bar{x}<40=5.71)$. However, it must be underlined that both groups rate the attention they pay to own personal data above average $(\overline{\mathrm{x}} 47=5.99)$, although this interest is not evenly distributed among the two groups. In terms of online behavior, there are also significant differences between the two age groups (F49 $=15,210$, $\mathrm{p} 49=0,000)$. The group of respondents over 40 rated their online behavior as more conscious $(\overline{\mathrm{x}}>40=6.42)$ than the younger group $(\overline{\mathrm{x}}<40=5.67)$. The older group is also more cautious $(\overline{\mathrm{x}}>40$ $=6.44)$ with regard to online consumer behavior $(\mathrm{F} 50=11.557, \mathrm{p} 50=0.001)$. Although both groups do not indecisively deal with their personal data, but rather attentively, it can be said that, in general, people over 40 evaluate themselves more carefully with regard to the information output, regardless of whether online or not. The question that arises is whether the age group over 40 is really more aware of the data collection and data processing measures, or simply underestimate the data collection and processing abilities.

Table 5. Discriminant analysis regarding appreciation of one's personal data

\begin{tabular}{|l|l|l|l|l|}
\hline \multicolumn{1}{|c|}{ Item } & \multicolumn{1}{c|}{$\begin{array}{c}\overline{\mathbf{x}} \\
\text { Age: }<\mathbf{4 0}\end{array}$} & \multicolumn{1}{c|}{$\begin{array}{c}\overline{\mathbf{x}} \\
\text { Age: }>\mathbf{4 0}\end{array}$} & \multicolumn{1}{|c|}{ F } & $\begin{array}{c}\mathbf{p} \\
\text { Value }\end{array}$ \\
\hline $\begin{array}{l}\text { 43. I prefer suggestions received from a cognitive computing } \\
\text { system, rather than those received from an employee. }\end{array}$ & 3.56 & 3.96 & 2.224 & 0.138 \\
\hline $\begin{array}{l}\text { 44. I believe that the cognitive computing systems used by } \\
\text { companies help to improve my consumer experience. }\end{array}$ & 4.60 & 4.92 & 1.452 & 0.230 \\
\hline $\begin{array}{l}\text { 45. I am aware of the ability of cognitive computing systems to } \\
\text { take data. }\end{array}$ & 5.58 & 5.92 & 2.551 & 0.113 \\
\hline
\end{tabular}




\begin{tabular}{|c|c|c|c|c|}
\hline Item & $\begin{array}{c}\bar{x} \\
\text { Age: }<40\end{array}$ & $\begin{array}{c}\bar{x} \\
\text { Age: }>40\end{array}$ & $\mathbf{F}$ & $\begin{array}{c}\text { p } \\
\text { Value }\end{array}$ \\
\hline $\begin{array}{l}\text { 46. I am aware of the ability of cognitive computing systems to } \\
\text { process data. }\end{array}$ & 5.66 & 6.00 & 2.542 & 0.113 \\
\hline $\begin{array}{l}\text { 47. I always take care of what data or information I provide in } \\
\text { an email or in a call to a company. }\end{array}$ & 5.71 & 6.48 & 15.719 & 0.000 \\
\hline $\begin{array}{l}\text { 48. I always take care of what data or information I provide as } \\
\text { a consumer in any type of interaction with a company. }\end{array}$ & 5.72 & 6.48 & 16.444 & 0.000 \\
\hline 49. I pay attention to my behavior in the online environment. & 5.67 & 6.42 & 15.210 & 0.000 \\
\hline $\begin{array}{l}50 . \text { I always take care of what data or information I provide as } \\
\text { a consumer in the online environment. }\end{array}$ & 5.79 & 6.44 & 11.557 & 0.001 \\
\hline
\end{tabular}

Source: Authors' own research.

\section{Conclusion}

In the past few years, the development of applications and automated systems designed to keep the relationship between customer and company has suffered important changes. Companies shifted the responsibility of offering direct human contact to cognitive systems that can take care of customer preferences and analyze by themselves consumer desires. With the significant help of cognitive computing, customer data can be directly used for several purposes such as advertising, targeting or even strategic decision making.

Our research underlines some differences in perception between age groups, but the two are related in many more aspects, than they are actually differentiated. Striking results can be seen when comparing the two age groups, especially with regard to data collection by cognitive systems and use of personal data by companies. Although attentive behavior seems characteristic for both groups (both scoring over the mean), this aspect is predominant for the older sample. Consumers older than 40 years do not really recognize that today every piece of data is perceived as unstructured data and will eventually be transformed into valuable information. Unaware of the importance of big data, they just think to be careful while the younger ones, although aware, know that they cannot really stop the process of data collection and processing.

Overall, our research indicates positive consumers' perceptions of cognitive systems on all studied variables, with an answering tendency of little above or around the middle scale point. Of course, this could be also interpreted as the common central tendency bias respondents are confronted with when rating their level of agreement on a scale from 1 to 7 . A further recognized behavioral distortion is also worth mentioning. For our research, the availability bias was identified. According to this, consumers are only then aware of certain aspects if they are made aware of them (John et al., 2009). As in this case: perhaps the respondents were only made aware of the power of cognitive systems through the questionnaire and thus formed an opinion, without actually interacting with such a system in real life.

In view of the broad applications of cognitive computing and the numerous possible research directions, the topic remains to be explored. The rapid progress and dynamic developments in this area require constant updating and the state of research must be kept up to date. The more cognitive computing helps in the design and management of consumer experiences, the more important the investigation of its effects, consumer ideas and perceptions 
on the topic is needed. Due to the sharpening of consumer awareness proposed here, the consumer experiences with the help of cognitive computing will definitely change significantly in the current years, since the newly developed cognitive customer experience management is thus developing new emerging forms.

\section{References}

Appel, A.P., Gandour, F., \& Cabdello, H. (2017). Cognitive Computing: Where Big Data Is Driving Us. In Zomaya, A.Y., \& Sakr, S. (Eds.), Handbook of Big Data Technologies, 807-850, Springer.

Berger, J., Humphreys, A., Ludwig, S., Moe, W.W., Netzer, O., \& Schweidel, D.A. (2020). Uniting the Tribes: Using Text for Marketing Insight, Journal of Marketing, 84, 1-25.

Busu, C. \& Busu, M. (2018). Modeling the Circular Economy Processes at the EU Level Using an Evaluation Algorithm Based on Shannon Entropy, Processes, 6(11), Article 225.

Chen, Y., Argentinis, E., \& Weber, G. (2016). IBM Watson: How Cognitive Computing Can Be Applied to Big Data Challenges in Life Sciences Research, Clinical Therapeutics, 38(4), 688-701.

Cui, G., Wong, M.L., \& Lui, H.K. (2006). Machine Learning for Direct Marketing Response Models: Bayesian Networks with Evolutionary Programming, Management Science, 52(4), 597-612.

Demirkan, H., Bess, C., Spohrer, J., Rayes, A., Allen, D., \& Moghaddam, Y. (2015). Innovations with Smart Service Systems: Analytics, Big Data, Cognitive Assistance, and the Internet of Everything, Communications of the Association for Information Systems, 37(35), 733-752.

Duan, Y., Edwards, J.S., \& Dwivedi, Y.K. (2019). Artificial Intelligence for Decision Making in the Era of Big Data - Evolution, Challenges and Research Agenda, International Journal of Information Management, 48, 63-71.

Dziewanowska, K. (2015). Dimensions of Real and Virtual Consumer Experiences, Faculty of Management Working Paper Series (University of Warsaw), 9(4).

Fosso-Wamba, S., Akter, S., Edwards, A., Chopin, G., \& Gnanzou, D. (2015). How 'big data' can make big impact: Findings from a systematic review and a longitudinal case study, International Journal of Production Economics, 165, 234-246.

Grover, P., \& Kar, A. K. (2017). Big data analytics: A review on theoretical contributions and tools used in literature. Global Journal of Flexible Systems Management, 18(3), 203-229.

Gupta, S., Karb, A.K., Baabdullahc, A., \& Al-Khowaiterd, W.A.A. (2018). Big Data with

Cognitive Computing: A Review for the Future, International Journal of Information Management, 42, 78-89.

Gursoy, D., Chin, O.H., Lu, L., \& Nunkoob, R. (2019), Consumers Acceptance of Artificially Intelligent (AI) Device Use in Service Delivery, International Journal of Information Management, 49, 157-169.

Holmlund, M., Van Vaerenbergh, Y., Ciuchita, R., Ravald, A., Sarantopoulos, P., Villarroel Ordenes, F., \& Zaki, M. (2019). Customer Experience Management in The Age of Big Data Analytics: A strategic framework, Journal of Business Research, 116, 356-365.

Huang, M.H., \& Rust, R.T. (2018). Artificial Intelligence in Service, Journal of Service Research, 21(2), 155-172.

Hurwitz, J., Kaufman, M., \& Bowles, A. (2015). Cognitive Computing and Big Data Analytics. Hoboken: Wiley. 
Lu, L., Cai, R., \& Gursoy, D. (2019). Developing and Validating a Service Robot Integration Willingness Scale, International Journal of Hospitality Management, 80, 36-51.

McColl-Kennedy, J.R, Zaki, M., Lemon, K.N., Urmetzer, F. \& Needly, A. (2019): Gaining Customer Experience Insights that Matter, Journal of Service Research, 22(8), 8-26.

Pelau, C., Ene, I. \& Pop, M.I. (2021). The impact of artificial intelligence on consumers' identity and human skills, Amfiteatru Economic, 23(56), 33-45.

Pelau, C., \& Acatrinei, C. (2019). The Paradox of Energy Consumption Decrease in the Transition Period towards a Digital Society, Energies, 12(8), Article 1428.

Pop, N.Al., \& Pelau, C. (2017). Correlations within the EFQM Business Excellence Model by Applying a Factor Analysis, Amfiteatru Economic, 44, 28-40.

Reynolds, H. (2015). Big Data and Cognitive Computing, Cognitive Computing Consortium.

Rust R.T., \& Huang, M.H. (2014). The Service Revolution and the Transformation of Marketing Science, Marketing Science, 33(2), 206-22.

Sabharwal, N., Barua, S., Anand N., \& Aggarwal, P. (2020). Developing Cognitive Bots Using the IBM Watson Engine, California: Apress.

Topol, E.J. (2019). High-performance medicine: the convergence of human and artificial intelligence, Nat Med, 25, 44-56.

Varadarajan, V., Kommers, P., Piuri, V., \& Subramaniyaswamy, V. (2020). Recent trends, challenges and applications in cognitive computing for intelligent systems, Journal of Intelligent \& Fuzzy Systems, 39, 8041-8041.

Zaki, M. (2019). Digital transformation: Harnessing Digital Technologies for the Next Generation of Services, Journal of Services Marketing, 33(4), 429-435.

Zbuchea, A., Pinzaru, F., Busu, M., Stan, S.O., \& Bargaoanu, A. (2019). Sustainable knowledge management and its impact on the performances of biotechnology organizations, Sustainability, 11(2), Article 359. 